\title{
Gênero, "o Corpo" e "Imitação Prestigiosa" na Cultura Brasileira
}

\section{Gender, "the Body" and "Prestigious Imitation" in the Brazilian Culture}

\author{
Mirian Goldenberg \\ Doutora em Antropologia Social. Professora do Programa de Pós- \\ Graduação em Sociologia e Antropologia do Instituto de Filosofia \\ e Ciências Sociais da Universidade Federal do Rio de Janeiro. \\ Endereço: Largo de São Francisco, número I, sala 418, Centro, CEP \\ 20051-070, Rio de Janeiro, RJ, Brasil. \\ E-mail: miriangoldenberg®uol.com.br
}

\section{Resumo}

Neste texto discute-se o papel do corpo como uma importante forma de capital (físico, simbólico e social) na cultura brasileira. Busca-se mostrar os traços distintivos de uma cultura em que o corpo é um elemento crucial na construção de uma identidade nacional, a partir das ideias de Gilberto Freyre, Marcel Mauss e Pierre Bourdieu. "O corpo" é um capital no universo pesquisado, um corpo distintivo que sintetiza três conceitos: 1) o corpo como uma insígnia (ou emblema) do esforço de cada um para controlar, aprisionar e domesticar o corpo a fim de conseguir a "boa forma", 2) o corpo como um ícone da moda (ou grife), que simboliza a superioridade daqueles que o possuem, e 3) o corpo como um prêmio (medalha), merecidamente conquistado por aqueles que foram capazes de alcançar uma forma física mais "civilizada", através de muito trabalho e sacrifício. Pode-se dizer que no Brasil "o corpo" é um capital, talvez um dos mais desejados pela classe média urbana e outros estratos sociais, que percebem "o corpo" como um veículo para a ascensão social, e também uma importante forma de capital no mercado de trabalho, no mercado de casamento e, também, no mercado erótico.

Palavras-chave: Gênero; Corpo; Sexualidade; Cultura Brasileira. 


\section{Abstract}

In this text I discuss the role of the body as an important form of physical, symbolic, and social capital in the Brazilian culture. I try to show the distinguishing traits of a culture in which the body is a crucial element in the construction of a national identity by calling forth the ideas of the Brazilian anthropologist Gilberto Freyre and the French anthropologists Marcel Mauss and Pierre Bourdieu. "The body" is a capital in the universe I have researched, a distinctive body which synthesizes three interrelated concepts: 1) the body as insignia (or emblem) of the effort each one has made to control, imprison, and domesticate the body in order to achieve "good shape"; 2) the body as a fashion icon (or brand), which symbolizes the superiority of those who possess it; and 3) the body as a prize (medal), deservedly earned by those who were able to achieve a more "civilized" physique through their hard work and sacrifice. It can be said that in Brazil the body is a capital, maybe the most desired one by the urban middle class and also by lower strata, which perceive the body as a fundamental vehicle for social ascension, and also an important form of capital in the job, spousal, and erotic markets.

Keywords: Gender; Body; Sexuality; Brazilian Culture.

\section{Introdução}

Nas últimas duas décadas, ao pesquisar homens e mulheres da classe média da cidade do Rio de Janeiro, tenho sido constantemente surpreendida pela frequência com que a categoria "o corpo" está presente no discurso dos meus interlocutores.

É importante reconhecer que não é possível generalizar a ideia de que "o corpo" é um importante valor na cultura brasileira como um todo. Essa ideia está presente de uma forma muito mais forte em um determinado segmento da classe média brasileira e, em particular, entre os moradores da cidade do Rio de Janeiro.

Este é um segmento social que pode ser descrito como predominantemente branco, heterossexual, com nível universitário, com uma renda alta, moradores da Zona Sul do Rio de Janeiro e, especialmente, nos bairros mais ricos da cidade (Leblon, Ipanema, Gávea, Lagoa, Jardim Botânico, Botafogo, Copacabana, Humaitá). Esses indivíduos constituem uma elite econômica, intelectual, política e cultural no Brasil. Têm poder material e simbólico e podem, consequentemente, construir e reproduzir corpos que são socialmente legitimados como hegemônicos.

Também, muitas vezes, esses indivíduos são a vanguarda de inúmeros brasileiros, pois os seus comportamentos, discursos e corpos são valorizados e reproduzidos por outros segmentos da população. Este grupo está, portanto, composto de indivíduos que são desejados, admirados, invejados e imitados por outros. Seus comportamentos e seus corpos estão constantemente retratados como normativos na mídia e, especialmente, nas telenovelas, programas de televisão, propagandas etc.

Acredito que a visão de mundo e o modo de vida desse segmento social têm um efeito multiplicador que vai muito além de seus limites de classe, o que sugere que ele pode ser útil para revelar em termos mais amplos as transformações experimentadas pela sociedade brasileira. Não se pode dizer, no entanto, que o universo por mim pesquisado possui "corpos brasileiros típicos". Mas é possível afirmar que "o corpo" apresentado por este grupo é de longe "o corpo" mais imitado pelos brasileiros em geral e, especialmente, por mulheres brasileiras.

Inicio esta reflexão no livro $N u$ \& vestido (Golden- 
berg e Ramos, 2002), ao analisar 1.279 questionários, respondidos por 835 mulheres e 444 homens, de 17 a 50 anos, com nível universitário, das camadas médias, moradores da cidade do Rio de Janeiro, Brasil. Focalizando as relações de gênero, busco compreender as expectativas, desejos afetivos e estereótipos sexuais de homens e mulheres de diferentes gerações. Desde 1988 realizo pesquisas que têm como foco as novas conjugalidades, a sexualidade, a infidelidade e a construção social do corpo na cultura brasileira.

Nesta pesquisa, procurei retomar os temas sobre os quais tenho refletido ao longo desses anos por meio de um novo caminho metodológico e com novas questões, surgidas a partir das transformações nos papéis de gênero. Com a preocupação de ampliar o espectro de meus estudos desenvolvidos anteriormente por meio de entrevistas em profundidade e observação participante, análise de trajetórias e reportagens da mídia, elaborei dois questionários focalizando as representações sobre ser homem e ser mulher, os modelos ideais de casamento, as diferentes experiências de relacionamentos afetivos e sexuais, entre outras questões.

\section{"Imitação Prestigiosa" na Cultura Brasileira}

Como afirmou Marcel Mauss (1974) é por meio da "imitação prestigiosa" que os indivíduos de cada cultura constroem seus corpos e comportamentos. Para Mauss, o conjunto de hábitos, costumes, crenças e tradições que caracterizam uma cultura também se refere ao corpo. Assim, há uma construção cultural do corpo, com uma valorização de certos atributos e comportamentos em detrimento de outros, fazendo com que haja um corpo típico para cada sociedade. Esse corpo, que pode variar de acordo com o contexto histórico e cultural, é adquirido pelos membros da sociedade por meio da "imitação prestigiosa". Os indivíduos imitam atos, comportamentos e corpos que obtiveram êxito e que têm prestígio em sua cultura. É importante destacar que este processo de imitação não é, necessariamente, um ato consciente dos membros de cada cultura.

No caso brasileiro, muitas das mulheres mais bem sucedidas, ricas e famosas, as mulheres "imi- táveis", são as atrizes, especialmente aquelas que são protagonistas das novelas exibidas no horário nobre. Mas, também, são objeto de imitação as modelos, cantoras e apresentadoras de televisão, todas elas tendo "o corpo" como o seu principal capital, ou uma de suas mais importantes riquezas. Por outro lado, os jogadores de futebol, os atores, cantores e apresentadores de televisão, que também têm o seu corpo como um importante capital, ocupam posições de muito sucesso, prestígio e dinheiro em nosso país.

Os corpos e os comportamentos mais imitados na cultura brasileira estão, sem dúvida alguma, nas telenovelas da Rede Globo. Elas podem ser vistas como um reflexo dos corpos e comportamentos existentes na sociedade, mas, ao mesmo tempo, mostram inovações comportamentais e novos estilos de vida. Muitas tramas das novelas da Rede Globo ganham destaque nas capas das principais revistas e jornais brasileiros. Muitas telenovelas exploram situações polêmicas e provocam discussões em todas as regiões do País, misturando ficção e realidade. Roupas, acessórios, cortes de cabelo, esmaltes, móveis, são imitados por mulheres e homens que assistem às novelas. Mais ainda, comportamentos e estilos de vida também se transformam quando veiculados pelas telenovelas da Rede Globo.

O Washington Post de 6 de junho de 2009 afirmou que o Brasil é o segundo país onde as pessoas mais assistem televisão, perdendo apenas para a Grã-Bretanha. As telenovelas, de acordo com o jornal, têm uma influência decisiva nas escolhas do estilo de vida dos brasileiros. É realmente difícil pensar o Brasil contemporâneo sem analisar a influência das telenovelas.

Segundo a mesma matéria do Washington Post, o Banco Interamericano de Desenvolvimento (BID) publicou dois estudos que demonstram a relação entre o consumo das telenovelas da Rede Globo e o declínio nas taxas de fertilidade e o crescimento das taxas de divórcio no País. A taxa de fertilidade no Brasil caiu vertiginosamente nos últimos cinquenta anos, de mais de seis filhos por família em 1960 para menos de dois no início do século XXI, observa o estudo. Essa queda é comparável à da China, mas sem quaisquer medidas de planejamento familiar.

A análise de 115 novelas da Globo entre 1965 e 
1999 mostrou que $72 \%$ das protagonistas femininas não tinha filhos e $21 \%$ tinha apenas um filho. As novelas mostravam a pequena, branca, saudável e urbana família consumista de classe média e média alta. As novelas, no Brasil, se tornaram um meio poderoso através do qual a família e os relacionamentos afetivos e sexuais foram idealizados.

Uma das mais bem-sucedidas novelas da rede Globo, "Viver a Vida", que foi ao ar em 14 de setembro de 2009, teve como protagonista uma mulher negra, fato marcante na história da televisão brasileira. Na trama, ela desempenhava o papel de uma linda e internacionalmente famosa top model brasileira. Todos os jornais e revistas brasileiros enfatizaram a importância do fato para a causa negra no Brasil, especialmente para as mulheres negras, tendo em vista que a quase totalidade das protagonistas das telenovelas são mulheres loiras ou morenas de peles claras e cabelos lisos.

As mulheres negras brasileiras ainda sofrem com a associação com o Carnaval, prostituição ou mesmo com a figura das empregadas domésticas. Apesar disso, hoje também é possível para uma brasileira negra ser uma atriz famosa, protagonista de novela e dona de um dos corpos mais admirados, desejados e imitados do País.

\section{"O Corpo" Brasileiro: miscigenado ou ianque?}

Gilberto Freyre (1987) apontava como modelo de beleza e de sensualidade da brasileira a atriz Sônia Braga: baixa, pele morena, cabelos negros, longos e crespos, cintura fina, ancas grandes, peitos pequenos. Dizia, com certo tom de crítica, que esse modelo "miscigenado" de brasileira estava sofrendo um "impacto norte-europeizante ou albinizante", ou ainda "ianque", com o sucesso de belas mulheres como Vera Fischer: alta, alva, loira, cabelos lisos ("arianamente lisos"), com um corpo menos arredondado.

No livro Modos de homem, modas de mulher, Freyre (1987) afirmou que:

Pode-se dizer da mulher que tende a ser, quanto a modas para seus vestidos, seus sapatos, seus penteados, um tanto maria-vai-com-as-outras. Portanto, a corresponder ao que a moda tem de uniformizante. Mas é da argúcia feminina a iniciativa de reagir contra essa uniformização absoluta, de acordo com características pessoais que não se ajustem a imposições de uma moda disto ou daquilo. Neste particular, é preciso reconhecer-se, na brasileira morena, o direito de repudiar modas norte-europeias destinadas a mulheres louras e alvas (Freire, 1987, p. 33).

Este novo modelo de beleza "ianque" para as brasileiras, já detectado por Freyre (1987), ganhou muito mais força nas últimas décadas. Como disse a revista Veja (o7/o6/200o): "As brasileiras não ficam velhas, ficam loiras", mostrando que a mulher brasileira é uma das maiores consumidoras de tintura de cabelo em todo o mundo. Além de Vera Fischer, citada por Freyre, e, posteriormente, Gisele Bündchen, outras modelos, atrizes e apresentadoras de televisão tornaram-se modelos a serem imitados pelas brasileiras, ícones "norte-europeizantes", diria Freyre.

Freyre (1987) enaltecia o corpo "miscigenado", um "corpo equilibrado de contrastes" e propunha uma consciência brasileira, dizendo que a mulher deveria seguir modas adaptadas ao clima tropical, em vez de seguir passivamente e, por vezes, grotescamente, modas de todo europeias ou americanas: na roupa, no sapato, no adorno, no penteado, no perfume, no andar, no sorrir, no beijar, no comportamento, no modo de ser mulher. Eu ainda acrescentaria, no corpo.

Gilberto Freyre (1987) sugeria que as modas e os modismos não diziam respeito apenas às roupas ou penteados, mas também poderiam se tornar modas de pensar, de sentir, de crer, de imaginar, e assim, subjetivas, influírem sobre as demais modas. Ele apontava os excessos cometidos pelas mulheres brasileiras mais inclinadas a seguir as modas, especialmente "as menos jovens, para as quais, modas sempre novas surgiriam como suas aliadas contra o envelhecimento" (p. 25).

Freyre (1987) ainda acrescenta que, mais de duas décadas atrás, várias novidades no setor de modas tendem a corresponder ao desejo das brasileiras menos jovens: o de rejuvenescer. E a verdade, dizia ele, é que há modas novas que concorrem para o rejuvenescimento de tais aparências, favorecido notavelmente por cosméticos, tinturas e cirurgias plásticas. 
$\mathrm{O}$ autor mostra, portanto, que as modas surgem visando uma preocupação central da mulher brasileira: permanecer jovem. Nessas últimas décadas, essa preocupação cresceu enormemente, com novos modelos de mulher a serem imitados: cada vez mais jovens, belas e magras.

Um exemplo do que dizia Gilberto Freyre é a polêmica causada pelo concurso de Miss Brasil, de 2005. Com o título: "Procura-se a mulher brasileira no Miss Brasil", o jornalista Jamari França (Globo On-line, 15/04/2005), afirmou que:

Parecia um concurso de miss de país europeu. As misses foram apresentadas de biquíni por região do país... Apresentadas uma a uma, as misses eram todas de uma pele alva de quem nunca se deixou queimar nas praias de água doce do Rio Amazonas... Até a Miss Bahia tem a pele branca de ascendência europeia... Quando chegou mais embaixo, nas regiões Sudeste e Sul, já não causava estranheza a presença de louras e morenas de olhos azuis ou verdes, já que é um biotipo mais comum nestas paragens. Não se trata de ficar com um preconceito racial às avessas contra as brancas, mas a realidade incontestável é que o concurso não reflete a diversidade de tipos da mulher brasileira. Muitas vezes quando uma miss entrava na passarela, a gente tinha impressão de que ela já tinha desfilado, tal a semelhança de tipos físicos. As nossas misturas, que resultam em mulatas de olhos verdes, beldades com traços indígenas e negras que assumem a raça com orgulho, botam muitas daquelas misses no chinelo. A impressão que se tem é que o concurso é aberto apenas à elite de cada estado, clubinhos fechados, sem que se procurem nas ruas mulheres que representem a nossa diversidade. A mulher brasileira é das mais belas do mundo, com uma riqueza que ouso dizer ufanisticamente que nenhum outro país tem. Pena que nem todas elas subam à passarela do concurso. Falta Brasil no Miss Brasil.

Um estudo interessante para discutir a especificidade do corpo brasileiro é o do antropólogo francês Stéphane Malysse. Ao comparar o corpo da mulher brasileira com o da francesa, Malysse constatou que:
[...] enquanto na França, a produção da aparência pessoal continua centrada essencialmente na própria roupa, no Brasil é o corpo que parece estar no centro das estratégias do vestir. As francesas procuram se produzir com roupas cujas cores, estampas e formas reestruturam artificialmente seus corpos, disfarçando algumas formas (particularmente as nádegas e a barriga) graças ao seu formato; as brasileiras expõem o corpo e frequentemente reduzem a roupa a um simples instrumento de sua valorização; em suma, uma espécie de ornamento (Malysse, 2002, p. 110).

Dentro dessa lógica, o autor diz que a tendência das adolescentes francesas a se vestir como suas mães mostra que a roupa, na França, participa de um processo de envelhecimento da aparência, enquanto no Brasil, pelo contrário, a tendência é vestir-se como jovem até bem tarde. Em algumas famílias que pesquisei no Rio de Janeiro, três gerações - filha, mãe e avó - compravam suas roupas nas mesmas lojas e, muitas vezes, compartilhavam as mesmas roupas e acessórios.

Malysse mostra que a distinção entre roupa de praia, roupa de cidade e roupa esportiva tende a desaparecer no Rio de Janeiro:

As roupas brincam com as partes escondidas/ expostas sem que o corpo se cubra muito mais ao passar da praia para a rua. Aqui, as formas femininas não são escondidas pelo efeito de camuflagem dos tailleurs, dos sobretudos ou dos cortes amplos, pelo contrário, são realçadas: as mulheres vestem saias e calças de cintura baixa, valorizando assim quadris e nádegas, colocandoos em relevo, em cena.... No Rio, as roupas são usadas, sobretudo, para valorizar as formas do corpo feminino, para exibi-las: a cintura e o busto são marcados, realçados... Esses corpos femininos trabalhados, moldados nas academias, só suportam roupas que deixem o corpo valorizado à mostra sob o tecido (Malysse, 2002, p. 112-113).

No Brasil, e mais particularmente no Rio de Janeiro, o corpo trabalhado, cuidado, sem marcas indesejáveis (rugas, estrias, celulites, manchas) e sem excessos (gordura, flacidez) é o único que, mesmo sem roupas, está decentemente vestido (Goldenberg e Ramos, 2002). 
Pode-se pensar, neste sentido, que, além de "o corpo" ser muito mais importante do que a roupa, ele é a verdadeira roupa: é "o corpo" que deve ser exibido, moldado, manipulado, trabalhado, costurado, enfeitado, escolhido, construído, produzido, imitado. É “o corpo" que entra e sai da moda. A roupa, neste caso, é apenas um acessório para a valorização e a exposição deste corpo da moda: "o corpo".

De acordo com o antropólogo americano Alexander Edmonds (2002), nas últimas décadas, o Brasil sofreu uma explosão da "indústria da beleza". A revista Time (o9/07/2001 Latin American Edition) chamou atenção para esse fato na capa que trouxe a dançarina Carla Perez com a seguinte legenda: The plastic surgery craze: latin american women are sculping their bodies as never before - along California lines. Is this cultural imperialism?. Segundo a Sociedade Brasileira de Cirurgia Plástica, o brasileiro, especialmente a mulher brasileira, tornou-se, logo após o americano, o povo que mais faz plástica no mundo. Em 2008, de acordo com números da Sociedade Brasileira de Cirurgia Plástica, 629.00o intervenções foram efetuadas no Brasil As mulheres compõem $88 \%$ dos que são operados. Mas o que torna o Brasil realmente especial nessa área é o ímpeto com que as mulheres decidem mudar o corpo e a rapidez com que a decisão de fazer uma cirurgia plástica é tomada. São três as principais motivações para fazer uma cirurgia plástica: atenuar os efeitos do envelhecimento, corrigir defeitos físicos e esculpir um corpo perfeito. No Brasil, esta última motivação é a que mais cresce: a busca de um corpo perfeito.

Como explicar este crescimento explosivo da indústria da beleza e a popularidade cada vez maior da cirurgia plástica? Edmonds (2002), cita mudanças estruturais das condições de trabalho, com mais mulheres trabalhando, mais competição e discriminação no local de trabalho, o que estimulou tanto o medo de envelhecer quanto o medo de engordar. Também a competição no mercado afetivo-sexual, extremamente desfavorável para as mulheres após os 30 anos, pode explicar o crescimento da cirurgia plástica no Brasil (Goldenberg, 2006). Os cirurgiões plásticos tendem a se apoiar em explicações objetivas para o crescimento da especialidade. Muitos mencionam as inovações técnicas da cirurgia, a reconhecida competência dos cirurgiões brasileiros, a facilidade do pagamento das cirurgias (em alguns casos, em prestações ou consórcios) ou o clima: o tempo quente levaria as brasileiras a exporem seu corpo seminu nas praias grande parte do ano.

Pesquisa mundial da Unilever mostrou que $63 \%$ das brasileiras querem fazer cirurgia plástica (o maior índice mundial da pesquisa). As americanas, por exemplo, ficaram em quarto lugar na pesquisa, com $25 \%$ desejando fazer plástica. E $89 \%$ das brasileiras gostaria de mudar algo no corpo. Sete em cada dez brasileiras deixam de fazer alguma atividade quando se sentem feias ou gordas (deixam de ir à praia, a festas e até ao trabalho). Entre as pesquisadas, as brasileiras são as que mais se enxergam como gordinhas e pouco sensuais.

Dos dez países investigados, o Brasil desponta como aquele em que as mulheres declaram estar mais preocupadas em ter um rosto bonito, a pele bem cuidada, o corpo em forma e uma imagem sexy. É também o país campeão em consumo de produtos para unhas, tinturas de cabelo e hidratantes para o corpo. Outro número impressiona: $58 \%$ das brasileiras afirmaram que, caso a cirurgia plástica fosse gratuita, recorreriam imediatamente ao bisturi.

As modelos brasileiras são muito bem sucedidas no mercado internacional da moda, o que torna a profissão uma das mais desejadas pelas crianças e adolescentes do País. A revista Veja (14/o7/1999) mostrou que "9 em cada 10 garotas do Brasil querem ser modelo". É importante lembrar que a modelo mais bem paga de todo o mundo e uma das mulheres mais ricas do mundo do entretenimento é a brasileira Gisele Bündchen.

O Brasil tem o maior consumo mundial per capita de remédios para emagrecer e de moderador de apetite. As overdoses de consumo, comuns no Brasil, podem ser muito perigosas e levar a ataques de pânico ou agressividade, além de alucinações, problemas respiratórios, convulsões, coma e até morte.

Bourdieu (1999) afirmou que os homens tendem a se mostrar insatisfeitos com as partes de seu corpo que consideram pequenas demais enquanto as mulheres dirigem suas críticas às regiões de seu corpo que percebem como grandes demais. 0 autor acreditava que a "dominação masculina", que constitui as mulheres como objetos simbólicos, 
tem por efeito colocá-las em permanente estado de insegurança corporal, ou melhor, de dependência simbólica: elas existem primeiro pelo, e para, o olhar dos outros, como objetos receptivos, atraentes, disponíveis. Delas se espera que sejam femininas, ou seja, sorridentes, simpáticas, atenciosas, submissas, discretas, contidas ou até mesmo apagadas. Neste caso, ser magra contribui para esta concepção de "ser mulher". Sob o olhar dos outros, as mulheres se veem obrigadas a experimentar constantemente a distância entre o corpo real, a que estão presas, e o corpo ideal, o qual procuram infatigavelmente alcançar.

Um exemplo deste tipo de dominação masculina é o que está ocorrendo no Brasil. A anorexia e a bulimia parecem ter evoluído da condição de patologia para a categoria de estilo de vida. Inúmeras páginas pessoais na internet divulgam movimentos próanorexia e pró-bulimia. São chamadas de "amigas da Ana" e "amigas da Mia", dando dicas para aquelas que desejam aderir a um estilo de vida que tem a magreza como modelo a ser seguido. Milhares de adolescentes brasileiras estão usando a internet para ensinar outras jovens a serem anoréxicas e bulímicas, pregando a inapetência e a autopunição sempre que comerem. As páginas são assustadoras com fotografias de meninas esquálidas apontadas como modelos de beleza, truques para enganar os pais e amigos para fingir que estão alimentadas e formas de se punir caso comam algo que engorda. Os sites divulgam os seguintes mandamentos: "Você não deve comer algo que engorda sem se punir depois. Ser magra é mais importante do que ser saudável. Ser magra é a coisa mais importante que existe. Não engula! Morda, mastigue e jogue fora! Durma pouco. Dessa forma você queima mais calorias. Limpe banheiros ou ambientes bem sujos. Você perde a fome".

Por outro lado, dentro da mesma lógica de dominação masculina, os homens são obrigados a serem fortes, potentes e viris. Inúmeros rapazes já morreram no Brasil por consumirem anabolizantes. Inúmeros adolescentes e meninos desenvolveram o distúrbio dismórfico corporal, representado por uma preocupação excessiva com supostas falhas na aparência, como o tórax pequeno ou o pênis diminuto. Basta uma rápida olhada na internet para descobrir o exagero de técnicas de aumento de pênis hoje comercializadas, sendo a indústria do aumento do pênis uma parte significativa da crescente indústria da imagem corporal masculina, estimulando e aumentando as inseguranças dos homens a respeito dos seus corpos. Homens, meninos e adolescentes sofrem silenciosamente, em segredo, uma vez que, em nossa sociedade, os "homens de verdade" não devem demonstrar preocupação com a aparência, pois podem ser considerados femininos ou acusados de serem homossexuais.

Para Pierre Bourdieu (1999), a estrutura impõe suas pressões aos dois termos da relação de dominação, portanto aos próprios dominantes, que são "dominados por sua dominação", fazendo um "esforço desesperado, e bastante patético, mesmo em sua triunfal inconsciência, que todo homem tem que fazer para estar à altura de sua ideia infantil de ser homem”. A preocupação dos rapazes e homens brasileiros com a altura, força física, medida do tórax, virilidade e, particularmente, com o tamanho do pênis, pode ser vista como exemplo desta dominação que o dominante também sofre.

O filósofo francês Gilles Lipovetsky (200o) analisou a "febre da beleza-magreza-juventude" que exerce uma "tirania implacável sobre a condição das mulheres". Para o autor, a obsessão com a magreza, a multiplicação dos regimes e das atividades de modelagem do corpo, os pedidos de redução de culotes e de modelagem de narizinhos arrebitados testemunham o poder normalizador dos modelos, um desejo maior de conformidade estética que se choca frontalmente com o ideal individualista e sua exigência de personalização dos sujeitos (p. 143).

Lipovetsky (2000) acrescentou que, de forma contraditória, quanto mais se impõe o ideal de autonomia individual, mais se aumenta a exigência de conformidade aos modelos sociais de corpo.

Retorno, então, ao antropólogo Gilberto Freyre (2002) para explorar sua ideia de "contrários em equilíbrio" ou "equilíbrio de antagonismos". Freyre dizia que no Brasil encontra-se o equilíbrio entre realidades tradicionais e modernas, sadistas e masoquistas, senhores e escravos, doutores e analfabetos, indivíduos de cultura predominantemente europeia e outros de cultura principalmente africana e ameríndia. "Talvez em parte alguma”, dizia ele, "se esteja 
verificando com igual liberdade o encontro, a intercomunicação e até a fusão harmoniosa de tradições diversas, ou antes, antagônicas, de cultura, como no Brasil” (Freyre, 2002, p. 123).

Pode-se enxergar melhor o paradoxo apontado por Lipovetsky (200o) com a ideia de "contrários em equilíbrio” de Gilberto Freyre. No Brasil, o desenvolvimento do individualismo e a intensificação das pressões sociais das normas do corpo caminham juntos. De um lado, o corpo da mulher brasileira se emancipou amplamente de suas antigas servidões - sexuais, procriadoras ou indumentárias. De outro, encontra-se, atualmente, submetido a coerções estéticas mais regulares, mais imperativas e mais geradoras de ansiedade do que antigamente.

Pode-se pensar, então, que as brasileiras vivem um "equilíbrio de antagonismos": um dos momentos de maior independência e liberdade femininas é também aquele em que um alto grau de controle em relação ao corpo se impõe à mulher brasileira.

\section{Uma Nova Moralidade: "a boa forma"}

Em seu clássico Casa Grande \& Senzala, publicado em 1933, o antropólogo Gilberto Freyre (2002), analisou a proeminência do corpo na formatação da identidade brasileira desde o início dos tempos coloniais, quando o colonizador português começou a desejar os corpos das índias e os fortes e belos corpos das escravas negras. Freyre defendeu que o corpo e a sexualidade exacerbada são elementos cruciais na construção da identidade brasileira.

A representação do Brasil como um paraíso tropical e sexual, presente na visão dos estrangeiros e também na dos próprios brasileiros, se mantém até os dias de hoje, reforçada pelas imagens de corpos seminus no Carnaval e nas praias.

Esta imagem é reforçada pelos cada vez mais frequentes relatórios que colocam o Brasil como um destino de turismo sexual. Várias pesquisas concedem aos brasileiros o título de campeões sexuais em termos de performance (que é quantificada de acordo com o número de parceiros, frequência de relações ou duração das preliminares sexuais).

Há menos de um século, apesar do calor tropical, os homens brasileiros usavam ternos com casaca, colete, colarinho e meias, e as mulheres se cobriam até o pescoço com roupas pretas ou cinza. A anatomia exposta dos dias de hoje parece confirmar que os brasileiros vivem em um tempo de inédita lassidão moral. O Brasil tornou-se conhecido internacionalmente como um oásis de liberdade sexual. O fluxo crescente de turismo sexual e a existência de trabalhadores do sexo de ambos os gêneros apenas reforçam na imaginação popular esta imagem do Brasil.

No entanto, um olhar mais cuidadoso no que parece ser a libertação do corpo do brasileiro mostra que não apenas há evidência de uma intensificação de códigos de moralidade e de decência, mas também sinais de uma nova "moralidade" que, por baixo de uma aparência de liberação física e sexual, impõe conformidade aos modelos estéticos convencionalmente chamados de "boa forma".

Em seu livro "O Processo civilizador" (1990), Norbert Elias apresentou as ferramentas básicas para a reflexão sobre esta "moral estética" em um momento no qual a liberdade corporal parece sem precedentes. $\mathrm{O}$ autor cita o exemplo das roupas de banho, para defender a ideia de que, uma maior exibição do corpo requer um maior autocontrole por parte das mulheres, a fim de se conformar ao "modelo civilizado" de comportamento. Controle muito maior do que quando o decoro mantinha seus corpos cobertos.

Nesta linha de pensamento, pode-se argumentar que a aparente liberação do corpo das brasileiras, amplamente exibido na publicidade, na mídia e nas interações do dia a dia, esconde um "processo civilizador". Sob esta nova "moralidade" - estar "em forma” -, a exibição do corpo requer dos indivíduos não apenas controle de seus impulsos, mas também o (auto) controle de sua própria aparência física. 0 decoro, antes restrito à não exibição dos corpos, é agora concentrado na obediência a um novo código para sua exibição.

Não são apenas modelos e atrizes que sofrem a pressão de ter que estar sempre "em forma”. Devido à influência exercida pela televisão, publicidade, jornais e revistas, a busca pela perfeição acaba por afligir os "simples mortais", bombardeados diariamente com imagens de rostos e corpos perfeitos, possivelmente manipuladas digitalmente para 
eliminar as menores imperfeições.

De acordo com a moralidade da boa forma, um corpo bem-cuidado, livre de marcas indesejáveis (rugas, estrias, manchas e celulite) e de excessos (gordura, flacidez) é o único que, mesmo sem roupas, parece decente. Como Courtine (1995) nos lembra em sua análise do corpo masculino americano no final do século 19, "o corpo masculino, se musculoso, nunca está realmente nu” (p. 96).

O exemplo dos trajes de banho citado por Elias (1990) nos permite analisar a força com que esta moralidade se impõe em lugares como o Rio de Janeiro, onde as praias e as altas temperaturas favorecem o uso de pouca roupa, tornando a cidade conhecida, tanto no Brasil como no estrangeiro, por sua informalidade, liberdade e sensualidade.

No entanto, um olhar mais atento basta para mostrar que a cultura carioca do corpo tem normas bem mais rígidas que parece à primeira vista. Com base nas inúmeras matérias com dicas, planos e sugestões para aprimorar a aparência, pode-se dizer que há uma variação sazonal (Mauss, 1974) das atitudes relacionadas ao corpo. No outono, deve-se tratar a pele e os cabelos danificados pelo sol; no inverno, seguir os controles dermatológicos para prevenir rugas, acne e manchas. $O$ inverno é também o momento propício para liftings, lipoaspirações, cirurgias nas pálpebras e no nariz, inserção de implantes nos seios. A primavera é a hora de "recuperar o tempo perdido" e entrar em forma para o verão.

A gordura é o inimigo número um na batalha pela boa forma - é quase uma doença, para aqueles que querem exibir um corpo "sarado", ícone da cultura da malhação. Fischler (1995) afirma que uma das características definidoras do nosso tempo é a "lipofobia", a obsessão com o peso e uma aversão quase maníaca à obesidade.

Nesta cultura, adepta de julgar, classificar e rotular as pessoas com base em sua aparência física, não ser gordo não basta - deve-se também cultivar um corpo firme, tonificado e musculoso (Lipovetsky, 2000). Gordura e flacidez são consideradas um símbolo tangível de falta de disciplina, preguiça, desleixo, quase um defeito moral que se reflete na falta de vontade de trabalhar o próprio corpo.

Em um contexto em que a beleza e a forma física não são mais percebidas como "uma dádiva divina da natureza", mas sim como o resultado do esforço individual, as pessoas têm responsabilidade por sua aparência. Sant'Anna (1995) observa que, diferentemente da primeira metade do século XX, quando Natureza era escrita com letras maiúsculas e era considerado perigoso interferir no próprio corpo em nome de objetivos pessoais ou vontades incutidas pela moda, hoje a liberdade de agir sobre o próprio corpo é incessantemente reforçada e estimulada. Através da prática de exercícios regulares, bons hábitos alimentares, cirurgia estética, tratamentos dermatológicos e cosméticos, presume-se que a perfeição estética seja alcançável e responsabilidade individual.

Neste processo no qual a responsabilidade sobre o corpo cabe a cada indivíduo, baseada no princípio da autonomia em construir-se, a mídia brasileira e sobretudo a publicidade desempenham papel fundamental. O corpo passou a ser "a commodity mais bela" (Baudrillard, 1991) e a publicidade, antes limitada a chamar atenção para um determinado produto e exaltar suas virtudes, hoje serve, principalmente, para promover o consumismo como estilo de vida. A publicidade criou um produto próprio: o consumidor, perpetuamente inquieto e insatisfeito com relação a sua aparência (Lasch, 1983). Os vencedores são, entre muitos outros, os cosméticos, a indústria da cirurgia plástica e o mercado da malhação.

Se por muitos séculos as pessoas foram levadas a acreditar que seus corpos não lhe pertenciam, hoje, após um longo período de puritanismo, as pessoas são coagidas a acreditar que o corpo é o objeto central da existência e dos afetos. Como afirma Baudrillard (1991), o culto da higiene, da dieta e da terapia que cultua a juventude, elegância, virilidade e feminilidade, bem como os cuidados, rituais e sacrifícios ligados ao "mito do prazer", tudo hoje em dia é testemunha do fato que o corpo passou a ser cultuado como um objeto de "salvação". Em sua função moral e ideológica, o corpo literalmente ocupou o lugar que antes pertencia à alma, afirma o autor.

\section{"O Corpo" como Capital}

É dentro deste quadro que analiso a categoria "o corpo" que apareceu na pesquisa realizada com homens e mulheres das classes médias cariocas. 
Surpresa com a recorrência dessa categoria, em uma pesquisa que investigava os valores e comportamentos a respeito de temas como sexualidade, casamento e infidelidade, descobri que "o corpo" é um valor e, também, uma verdadeira riqueza no universo pesquisado.

Quando apresentadas à questão: "O que você mais inveja em outras mulheres?", a resposta mais comum das mulheres foi: a beleza, em primeiro lugar, com "o corpo" vindo em seguida e a inteligência em terceiro. Quando os homens responderam o que mais invejam em outros homens, as respostas foram: inteligência, situação financeira, beleza e "o corpo".

Em outra questão, perguntando às mulheres: "O que mais te atrai em um homem?". Obtive como resposta: inteligência e "o corpo". Quando perguntei aos homens: "O que mais te atrai em uma mulher?", encontrei: beleza, inteligência e "o corpo" "O corpo" apareceu ainda com maior destaque quando perguntei às mulheres: "O que mais te atrai sexualmente em um homem?" As respostas foram: tórax e "o corpo". Também perguntei para os homens: "O que mais te atrai sexualmente em uma mulher?" Tive como resposta: "bunda" e "o corpo".

É interessante a recorrência da categoria "o corpo" como um objeto de desejo, algo que é admirado não apenas pelas mulheres, mas também, de forma expressiva, pelos homens. 0 mais instigante é que "o corpo" é nomeado dessa forma, sem a ajuda de qualquer adjetivo, quase como se fosse uma entidade autônoma, independente e abstrata.

Em outra questão da pesquisa, convidei os participantes a dizerem como, hipoteticamente, eles se descreveriam em um anúncio buscando um parceiro amoroso e como eles descreveriam o parceiro que estariam procurando. Em suas respostas, "o corpo" veio acompanhado de palavras como: esculpido, bem definido, atlético, forte, trabalhado, saudável, bonito, atraente, sexy, gostoso, entre outros inúmeros adjetivos.

Alguns exemplos dos anúncios dos pesquisados podem ilustrar melhor o que encontrei nas respostas:

Sou uma mulher magra, jovem, cabelos longose lisos, bonita. E também muito sexy!

Procuro um homem de corpo sarado, muito masculino e romântico!
Sou alto, moreno, forte, bem-dotado, inteligente e rico.

Procuro uma mulher loira de cabelo longo, cintura fina, seios firmes e bumbum bonito, de corpo lindo e muito gostosa.

É interessante destacar que "o corpo" aparece com destaque em respostas às questões sobre inveja, admiração, atração e nos anúncios buscando um parceiro. Quando eles e elas respondem o que invejam, sentem-se atraídos ou admiram, "o corpo" aparece sem adjetivos - é simplesmente "o corpo".

Apenas nos anúncios "o corpo" aparece adjetivado. Apenas aí nos tornamos mais conscientes de que ideal de corpo é construído, quando os pesquisados se referem abstratamente a "o corpo". Não se trata de um corpo indistinto, dado pela natureza, mas sim de um corpo trabalhado, sarado, malhado, esculpido, saudável. Um corpo "natural" paradoxalmente cultivado, uma cultura tornada natural (Bourdieu, 1987).

A cultura da beleza, da "boa forma" e da aparência física, baseada em certas práticas, transforma o corpo "natural” em um corpo "distintivo" (Bourdieu, 1988).

"O corpo" na pesquisa realizada com homens e mulheres das classes médias do Rio de Janeiro apareceu como um corpo coberto por sinais distintivos. Sua exibição e desnudamento públicos podem dar a impressão de um corpo mais livre, mas, na verdade, como tenho sugerido, ele permanece prisioneiro a normas sociais internalizadas pelos indivíduos.

Pode-se dizer que "o corpo" e tudo o que ele simboliza estimula nos brasileiros a conformação a um estilo de vida e a um código de conduta. A obediência a estas normas é recompensada pelo sentimento de pertencer a um grupo "superior". "O corpo" é um valor em si, que simultaneamente identifica o indivíduo com um grupo e o distingue dos demais. Esse corpo malhado, esculpido e desenhado constitui uma espécie de prova de virtude. Sob a moralidade da boa forma, trabalhar o corpo é um ato prenhe de significado.

O corpo, muito mais do que as roupas, transforma-se em símbolo que consagra e torna evidente as diferenças entre classes sociais. Ele sintetiza três ideias: 1) o corpo como insígnia (ou emblema) do esforço que cada um faz para controlá-lo e domesticá-lo 
até atingir a "boa forma"; 2) o corpo como ícone da moda, que demarca a superioridade daqueles que possuem "o corpo da moda"; e 3) o corpo como medalha ou prêmio, merecidamente conquistado por aqueles que conseguiram um físico mais "civilizado" por meio de um trabalho duro e muito sacrifício.

Minha pesquisa sugere que, entre os cariocas de classe média e mesmo entre brasileiros mais pobres, o capital social literalmente incorporado pelo corpo é de enorme importância. Para os primeiros, o corpo é uma fonte de distinção e de sucesso. Para os últimos, pode ser visto como um meio de mobilidade social. Para todos, "o corpo" em "boa forma" é considerado um verdadeiro capital nos mercados afetivo, sexual e, também, no mercado de trabalho.

\section{Referências}

BAUDRILLARD, J. A Sociedade de consumo. Lisboa: Edições 70, 1991.

BOURDIEU, P. A economia das trocas simbólicas. São Paulo: Perspectiva, 1987.

BOURDIEU, P. La distinctión. Madri: Taurus, 1988.

BOURDIEU, P. O poder simbólico. Lisboa: Difel, 1989.

BOURDIEU, P. A Dominação masculina. Rio de Janeiro: Bertrand Brasil, 1999.

COURTINE, J. J. Os staknovistas do narcisismo: body-building e puritanismo ostentatório na cultura americana do corpo. In: SANT'ANNA, D. B. Políticas do corpo. São Paulo: Estação Liberdade, 1995. p. 81-114.

EDMONDS, A. No universo da beleza: notas de campo sobre cirurgia plástica no Rio de Janeiro. In: GOLDENBERG, M. (org.). Nu \& vestido: dez antropólogos revelam a cultura do corpo carioca. Rio de Janeiro: Record, 2002. p. 189-261.
ELIAS, N. O processo civilizador: uma história dos costumes. Rio de Janeiro: Jorge Zahar Editor, 1990.

FISCHLER, C. Obeso benigno, obeso maligno. In: SANT'ANNA,D. B. Políticas do corpo. São Paulo: Estação Liberdade, 1995. p. 69-80.

FREYRE, G. Modos de homem, modas de mulher. Rio de Janeiro: Record, 1987.

FREYRE, G. Casa-grande \& senzala. Rio de Janeiro: Record, 2002.

GOLDENBERG, M.; RAMOS, M. S. A civilização das formas: o corpocomo valor. In: GOLDENBERG, M. (org.). $N u$ \& vestido: dez antropólogos revelam a cultura do corpo carioca. Rio de Janeiro: Record, 2002. p. 19-40.

GOLDENBERG, M. Infiel: notas de uma antropóloga. Rio de Janeiro: Record, 2006.

LASCH, C. A Cultura do narcisismo: a vida americana numa era de esperanças em declínio. Rio de Janeiro: Imago, 1983.

LIPOVETSKY, G. A terceira mulher. São Paulo: Companhia das Letras, 2000.

MALYSSE, S. Em busca dos (H)alteres-ego: olhares franceses nos bastidores da corpolatria carioca. In: GOLDENBERG, M. (org.). Nu \& vestido: dez antropólogos revelam a cultura do corpo carioca. Rio de Janeiro: Record, 2002. p. 79-137.

MAUSS, M. As técnicas corporais. Sociologia e antropologia. São Paulo: EPU/EDUSP, 1974.

SANT'ANNA, D. B. Políticas do corpo. São Paulo: Estação Liberdade, 1995.

UNILEVER. Dove: mais que um sabonete. São Paulo, Centro de História Unilever. Disponível em: $<$ http://www.unilever.com.br/Images/Dove_tcm95106355.pdf $>$. Acesso em: 15 jan. 2010. 